\title{
Sustainability and public health nutrition at school: assessing the integration of healthy and environmentally sustainable food initiatives in Vancouver schools
}

\author{
Jennifer L Black ${ }^{1, *}$, Cayley E Velazquez', Naseam Ahmadi ${ }^{1}$, Gwen E Chapman ${ }^{1}$, \\ Sarah Carten ${ }^{2}$, Joshua Edward ${ }^{1}$, Stephanie Shulhan ${ }^{1}$, Teya Stephens ${ }^{1}$ and Alejandro Rojas ${ }^{1}$ \\ ${ }^{1}$ Faculty of Land and Food Systems, Food Nutrition and Health, University of British Columbia, 2205 East Mall, \\ Vancouver, BC V6T 1Z4, Canada: ${ }^{2}$ Vancouver Coastal Health Authority, Vancouver, BC, Canada
}

Submitted 20 February 2014: Final revision received 8 January 2015: Accepted 19 January 2015: First published online 16 March 2015

\begin{abstract}
Objective: To describe the development and application of the School Food Environment Assessment Tools and a novel scoring system to assess the integration of healthy and environmentally sustainable food initiatives in elementary and secondary schools.

Design: The cross-sectional study included direct observations of physical food environments and interviews with key school personnel regarding food-related programmes and policies. A five-point scoring system was then developed to assess actions across six domains: (i) food gardens; (ii) composting systems; (iii) food preparation activities; (iv) food-related teaching and learning activities; and availability of (v) healthy food; and (vi) environmentally sustainable food.

Setting: Vancouver, Canada.

Subjects: A purposive sample of public schools ( $n$ 33) from all six sectors of the Vancouver Board of Education.

Results: Schools scored highest in the areas of food garden and compost system development and use. Regular integration of food-related teaching and learning activities and hands-on food preparation experiences were also commonly reported. Most schools demonstrated rudimentary efforts to make healthy and environmentally sustainable food choices available, but in general scored lowest on these two domains. Moreover, no schools reported widespread initiatives fully supporting availability or integration of healthy or environmentally sustainable foods across campus.

Conclusions: More work is needed in all areas to fully integrate programmes and policies that support healthy, environmentally sustainable food systems in Vancouver schools. The assessment tools and proposed indicators offer a practical approach for researchers, policy makers and school stakeholders to assess school food system environments, identify priority areas for intervention and track relevant changes over time.
\end{abstract}

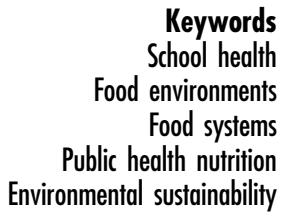

Keywords onvironments ood systems Environmental sustainability
Consuming a sufficient, safe and nutritious diet is critical for human growth and development and for reducing chronic disease risk later in life ${ }^{(1-3)}$. Dietary practices can also have substantial environmental implications, shaped by the ways that food is produced, processed and transported, and how food waste is managed ${ }^{(4-7)}$. Advocates for a healthy and more environmentally sustainable food system are therefore urging the general public and public institutions to consider both the health consequences of poor dietary quality as well as the significant social and ecological costs of food system outputs and food choices ${ }^{(5,7)}$. These issues are particularly critical for children, whose future health and that of the world they will grow up in is affected by the current food system. Schools are therefore promising spaces where children and their families can potentially cultivate positive food practices and understandings about food systems. What students learn inside and outside classrooms can shape how young people think about connections between where food comes from and environmental costs, and can have persisting impacts on personal health and the ecosystems within which schools are situated ${ }^{(8)}$.

Despite increasing research and advocacy calling for improved availability of healthy foods at school, school-based actions to increase the environmental sustainability of the 
food system are relatively sparse in North America ${ }^{(9-11)}$. Sustainable food initiatives are, however, gaining traction in some school districts, occasionally accompanying more traditional nutrition education and health promotion approaches. For example, many school districts across the USA and some in Canada now have Farm to School programmes providing fresh, locally grown fruit and vegetables to students and are often supplemented with nutrition and/or sustainable agriculture education programmes $^{(12,13)}$. Increased access to sustainable foods is hypothesized to improve students' knowledge and attitudes regarding healthy and sustainable eating and likely contribute to increased intake of healthy foods such as fruit and vegetables ${ }^{(14-16)}$.

Few studies to date have comprehensively evaluated the extent to which schools support healthy eating (e.g. through the availability of fresh fruits and vegetables and foodrelated learning activities) and integrate environmentally sustainable food choices into school food environments (e.g. by offering opportunities to grow food or reduce food waste on school grounds, or by providing minimally processed, locally and sustainably grown options). As efforts to improve school food systems mature, both subjective and objective indicators will be critical for documenting the complex nature of how and where progress is made and which interventions are most effective. Despite the growing need for user-friendly evaluation approaches, few indicators exist for use in diverse school contexts. Existing tools largely evaluate only narrow components of school food environments such as local food procurement policies or access to healthy food in lunch programmes, but seldom concurrently consider multiple facets of complex school food systems. Moreover, it is difficult to compare changes over time or progress between schools because there is no standard language or scale for describing a school's level of engagement in food system actions.

The present study therefore emerged in response to the need for a pragmatic approach for characterizing and comparing school food environments. The objectives of the present study were to: (i) describe the development of the School Food Environment Assessment Tools (SFEAT) which include a qualitative scoring system to assess the extent to which schools have integrated healthy and environmentally sustainable food initiatives; (ii) characterize a sample of elementary and secondary schools in Vancouver, Canada using the proposed scoring system; and (iii) identify opportunities for applying this approach for future research, monitoring and to inspire school-based actions. This work is part of (and directly informed by) a community-university research alliance called the Think\&EatGreen@School project which evolved over a decade through a collaboration between the Vancouver Board of Education, the University of British Columbia and several community partners ${ }^{(8,17)}$. Vancouver is an opportune context for studying school food system changes given the growing network of government, academic and community-based agencies working on school health, sustainability and food system issues and school board support for improving dietary health and reducing carbon emissions in school buildings ${ }^{(17-20)}$.

\section{Theoretical framework and working definitions}

For the present study, the 'school food environment' was broadly defined and incorporated the core pillars of the comprehensive school health (CSH) framework ${ }^{(21,22)}$ which include: (i) the macro-level school health policy environment (e.g. school, district and provincial policies that support food and sustainability initiatives); (ii) the social and physical environment (e.g. design of eating spaces, food gardens and compost systems, what foods are available, where and for what price); (iii) teaching and learning (e.g. where healthy eating, environmentally sustainable food practices, food skills and food literacy are embedded in curricula); and (iv) partnerships and services (e.g. vendors and food-service workers who source, prepare and sell food, or support foodrelated initiatives). Definitions from the four $\mathrm{CSH}$ pillars were supplemented with additional factors from the local context and literature about amenities and programmes supporting healthy eating and environmentally sustainable food systems. For example, physical environments in CSH typically describe features such as playgrounds and buildings, but are augmented here with food system amenities including gardens and compost systems.

For the present study, the definition of healthy eating was guided primarily by national dietary recommendations articulated in Canada's Food Guide ${ }^{(23)}$. Assessment of nutritious food availability focused largely on foods prioritized by provincial and national health interventions aimed at increasing compliance with Food Guide recommendations, including increased intake of fruit, vegetables, low-fat dairy and whole grains. Foods described here as 'unhealthy' were operationalized based on provincial nutritional guidelines which prohibit the sale of food items that fail to meet limits regarding serving sizes, energy content, fat, added sugar, saturated and trans fats, sodium and caffeine, or that do not contain minimum values for some essential nutrients ${ }^{(24)}$.

'Environmentally sustainable' food was defined based on current best practice guidelines articulated by national and international agencies ${ }^{(7,25,26)}$. While fully explicating current nutrition and sustainability guidelines is beyond the scope of the present paper, the study focused on several key tenets espoused by recent consensus statements related to sustainable food systems including the availability of foods that are minimally processed, grown or sourced locally, seasonally and organically, include vegetarian options and create less waste from packaging ${ }^{(7,25,26)}$.

\section{Experimental methods}

\section{Tool development and refinement}

Given the complexity of school food environments, a crucial step of the present study was to identify existing 
school-based measures through a systematic literature search and via consultation with a wide variety of local stakeholders. Thirty-five documents were identified and reviewed, including surveys, school self-assessments and reports related to healthy or sustainable eating, food environments and policy, funding and programming. While the majority of resources identified were developed or used in the USA, eight were from Canada ${ }^{(27-34)}$ and one was identified from each of Wales ${ }^{(35)}$, New Zealand ${ }^{(36)}$ and Australia ${ }^{(37)}$. All tools examined some facet of schoolrelated health, nutrition or students' food practices, but less than one-third explicitly examined sustainability concepts. In general, sustainability-related questions were brief and most commonly focused on local food procurement policies, availability of farm to school programmes or school gardening initiatives. Relevant questions were selected from ten tools ${ }^{(27,30,31,35,38-43)}$, adapted where necessary and additional questions were created to fill noted gaps. Moreover, standards outlined in provincial policy documents including the School Meal and School Nutrition Program Handbook ${ }^{(32)}$ and the Guidelines for Food and Beverage Sales in British Columbia (BC) Schools (hereafter referred to as the Guidelines) ${ }^{(24)}$ were carefully reviewed. Questions were subsequently developed to examine the extent to which schools implemented programmes and policies of interest.

Two versions of the SFEAT data collection tool were developed: one for elementary schools (kindergarten to grade 7 in most Vancouver schools) and one for secondary schools (generally grades 8 to 12). The versions overlapped for most core measures, but accounted for known differences between Vancouver elementary- and secondary-school food contexts. Unlike the USA, there is no federally funded school meal programme in Canada. Instead, foods are available from a variety of sources including cafeterias, subsidized lunch programmes (available only at some schools), vending machines, school stores, fundraisers and special food days, and/or food provided by parents or community groups, which vary between elementary and secondary schools ${ }^{(34)}$. Tools were reviewed by co-investigators and project partners to ensure face and content validity and clarity of questions, and were tested for feasibility at six elementary schools from diverse areas of the city and one secondary school during the 2010-2011 school year. The study met the guidelines laid down in the Declaration of Helsinki and all procedures involving human subjects were approved by the Behavioural Research Ethics Board at the University of British Columbia and the Vancouver Board of Education. Written consent was obtained from participating school stakeholders.

\section{Data collection}

Purposive sampling was used to recruit a representative set of Vancouver's public elementary and secondary schools and included schools from diverse neighbourhoods in terms of geographic location, socio-economic status, surrounding food environment characteristics and commercial densities. All Think\&EatGreen schools were offered the SFEAT assessment as a component of project participation. Sampling aimed to recruit an equal number of schools engaged in the Think\&EatGreen@School project and schools with no previous relationship to the study team. Purposive sampling ensured that at least one elementary and one secondary school from each of Vancouver Board of Education's six geographic sectors was included in the study. Of the pilot schools, three of the elementary schools and the one secondary school were assessed a second time and included in the final analytic sample.

Data collection had three main components beginning with direct observations of each school's physical food environment. This included open-ended questions for characterizing available eating spaces, places where food is sold (e.g. cafeterias, vending machines, fundraisers) and the presentation of available food items. Itemized lists then examined the extent of availability of food items that align with nutrition (and sustainability) targets, such as fresh fruit and vegetables, non-flavoured low-fat milk and whole grains, and of minimally nutritious items that contravene the Guidelines, such as deep-fried foods and sugar-sweetened beverages. The second section involved an interview with a key stakeholder (usually a food-service worker or teacher) inquiring about available programmes and policies related to healthy eating and sustainable food systems, including details about food procurement and sales. The final section included interview questions directed at a school administrator (principal or vice principal), who contributed additional insight regarding actions, concerns and goals related to healthy eating and sustainable food systems initiatives including composting and gardening programmes.

Data collection occurred over two school years; first, in September to December 2011 in twelve public elementary and nine secondary schools; and second, from November 2012 to April 2013 in an additional six elementary and six secondary schools. Trained research assistants made introductory visits approximately one month before data collection to familiarize themselves with the school layout, identify key informants and introduce themselves to personnel. When an in-person introductory visit was not feasible, initial contact was made via email or telephone. On the second visit, researchers conducted all observations and interviews in pairs when possible to verify and cross-check data.

\section{Domain development and scoring}

After data were entered and reviewed for accuracy and completeness, the research team collaboratively developed a set of six key domains and identified the corresponding indicator questions from data collection tools to inform the scoring of healthy and environmentally sustainable school food domains (Table 1). Domain selection was based on: (i) a Think\&EatGreen@School logic model 
Table 1 Description of the six food system environment domains, the School Food Environment Assessment Tools (SFEAT) indicator questions used to guide the scoring process and the interpretation of each score across the six domains

\begin{tabular}{lcl}
\hline SFEAT indicator questions used to inform scoring of each domain & Score & Interpretation of quantitative score \\
\hline Food gardens & 0 & No garden available and no food grown at school \\
- Is a school garden in existence? & 1 & School has just started growing some food or the existing garden is not well maintained \\
- What year was it established (i.e. is it a new garden)? & 2 & Garden is up and running well, but is not used regularly for multiple activities \\
- Which of the following school activities utilize the garden: (i) teaching about food & 3 & Garden is used regularly for several different activities \\
preparation; (ii) teaching about healthy eating; (iii) teaching about gardening skills; & 4 & Garden is well developed and is a significant part of the school community
\end{tabular}

(iv) teaching about science or other subjects; (v) using food grown for student purposes?

Composting systems

- Is a composting programme/system in existence?

- What year was it established (i.e. is it a new system)?

- Which of the following types of food waste are composted: (i) waste from the kitchen; (ii) waste from cooking classes; (iii) waste from students' meals or snacks in lunch room; (iv) waste from students' meals or snacks in the classroom(s); (v) waste from meals or snacks in staff room(s); (vi) school garden or yard waste?

- Where does finished compost end up (e.g. school garden or grounds, fundraisers, donated)?

Food preparation activities

- Are any school facilities or kitchens used for student food skill education or clubs/afterschool programmes that prepare food or work on cooking skills?

- How are the school facilities or kitchens used? By whom and how often?

- Are school gardens used to teach about food preparation? If so, how well utilized are they?

Other than home economics, are there courses that teach about food preparation? Which ones?

Food-related teaching and learning activities

- In which ways does the school integrate food and nutrition in the classroom (e.g. arts education, health education)?

- Are any school facilities or kitchens used for student education about food preparation or cooking? How are facilities used? By whom and how often?

- Are school gardens used for teaching and learning activities? By whom and how often are they used for these purposes?

- Are any school facilities used for teaching about food preparation or managing food/composting?

- In what ways is food integrated into the school curricula or teaching activities (e.g. science, physical education)?

No composting programme or system available at school

School has just started a composting programme or has a programme that is rarely used Composting programme is up and running, but is not widely available or used throughout the school

Composting programme is widely available and used throughout the school

Composting programme is well developed and is a significant part of the school community

No food preparation activities available at school

Occasional ('one-off') food preparation activities are available for some students

Regular food preparation activities are integrated into the curriculum or after-school activities for some grades, but are not available widely or used by most students

$3 \quad$ Food preparation activities are well integrated into school courses and activities; most students have opportunities to prepare food in multiple contexts

$4 \quad$ Food preparation activities are highly integrated; using healthy, local products, culturally diverse, supported by parent advisory councils, use products grown at school or with community partners

$0 \quad$ No food or sustainable food systems-related activities used for teaching Some food or sustainable food systems activities initiated, but infrequently

Food or sustainable food systems topics and activities are incorporated in multiple grades and classes, $50 \%$ or fewer grades are exposed

3 Integration of teaching and learning within food programmes, gardens, etc. is well developed; more than $50 \%$ of grades exposed

$4 \quad$ Well-developed integration of entire food cycle into teaching and learning activities for all classes and grades 
Availability of healthy food

- Which food programmes are available (e.g. BC Fruit and Vegetable Program, Milk Program, Farm to School, breakfast programmes, lunch programmes, food fundraisers, special food days)?

- How frequently are food fundraisers or special food days held? When they are held, what type of food is offered (e.g. hot dog, pizza, sushi)?

- Has the school recently increased the sale/availability of healthier items (e.g. fresh fruit, vegetables, dark green/orange vegetables, low-fat dairy, whole grains)?

- Has the school recently stopped the sale/availability of less healthy items (e.g. deepfried foods, sugar-sweetened beverages, foods prohibited by school nutrition guidelines)?

- Have events that encourage healthy food choices been held? What ones?

- Are healthy food items available (e.g. fruits, vegetables, lower-fat milk options, whole grains)? If yes, how often?

- Are unhealthy food items available (e.g. deep-fried items, sugar-sweetened

beverages)? If yes, how often?

- Are foods/beverages sold in vending machines, school stores and fundraisers in compliance with school nutrition guidelines?

Availability of environmentally sustainable food

- How often are the following foods available: minimally processed, locally grown/ sourced, organic, seasonal or vegetarian options?

- Do food purchasing policies support environmentally sustainable choices (e.g. minimally processed, locally sourced options, less packaging materials, reduced use of single serve packages, condiments in bulk, reusable dishware)?

- Have environmentally sustainable activities/programmes been held (e.g. waste free lunches, sustainability fairs)? Which ones and how often?

- How important is environmental sustainability when making school meal planning or purchasing decisions?

Foods provided or sold offer almost no healthy options and are almost always unhealthy foods

School tries to make some healthy options available and tries to limit unhealthy foods Healthy options are frequently, but not always available and unhealthy foods are rarely available

Healthy options are always available and unhealthy foods are rarely available

Providing healthy foods is fully supported and implemented by the school community 
that took the entire food system into consideration, from production through to waste management; (ii) an indicator selection and 'dotmocracy' exercise ${ }^{(44)}$ conducted in 2010 where over thirty diverse stakeholders including researchers, school administrators and community partners identified the most important metrics for monitoring changes in school food environments; and (iii) whether data from the SFEAT were available to assess proposed domains. The six most relevant domains identified by this process were: development and use of (i) food gardens; (ii) composting systems; (iii) food preparation activities; (iv) food-related teaching and learning activities; and availability of (v) healthy food; and (vi) environmentally sustainable food.

Domains were scored using a five-point scale, through an iterative and collaborative approach that involved co-investigators, research assistants and dietitians including a community nutritionist who worked with participating schools. Broadly, the scoring system was as follows: $0=$ nothing happening in this area; $1=$ initial steps have been taken; 2 =initiatives are happening regularly and engage some members of the school community; $3=$ initiatives are happening often and engage many members of the school community (in multiple ways if relevant); $4=$ exceptional progress has been made with full integration within the school. For each school, the team examined a mix of available qualitative and quantitative indicators for each domain (described in Table 1) and applied a scoring system to rate each school on each domain. Team discussion then added additional first-hand knowledge of particular school settings and reached consensus as to which descriptor best characterized that school (see last column in Table 1). While a quantitative coding system guided the initial scoring, the final scores reflect a hybrid approach that incorporated subjective opinion and interpretive reasoning to reach team consensus about final scores.

\section{Data analysis}

Descriptive statistics (e.g. median, range, frequencies) were used to characterize the distribution of domain scores across schools. Differences in score distributions were compared between elementary and secondary schools using Fisher's exact test (using $P<0.05$ to determine statistical significance) because $\chi^{2}$ test assumptions were violated (i.e. some cells had an expected count $<1$ or more than $20 \%$ had expected frequencies $<5)^{(45)}$. The final sample size was thirty-three for all domains except gardens ( $n$ 32) because there were insufficient data to reach consensus about garden use and development in one elementary school.*

\footnotetext{
* In this situation, garden-related data collection could not be completed and changes to the school garden programme shortly after the initial data collection period made it difficult to confirm the state of the garden programme at this one school.
}

\section{Results}

Participating schools drew from all geographic sectors of the city and represent all but four of Vancouver Board of Education's secondary schools and more than one-fifth of Vancouver's ninety-one elementary schools and annexes. This sample represents a diverse range of schools in terms of size and ethnic mix and socio-economic characteristics of the students served, and reflects Vancouver's demographic heterogeneity. Secondary schools are typically larger than elementary schools; 2010 school enrolments ranged from approximately 100 students for the smallest elementary school and one alternative secondary programme sampled, to over 2100 students for the two largest secondary schools. Median school size was 340 in sampled elementary schools and 1294 students among secondary schools $^{(46)}$. Over half of participating Think\&EatGreen schools volunteered to participate in SFEAT as a project activity and at the time of data collection, twenty schools (61\%) had been involved in some way with the Think\&EatGreen@School project. Thirteen schools (39\%) had no previous relationship to the study team and response rates were only marginally lower compared with Think\&EatGreen schools.

\section{Food gardens}

Figure 1 shows that $75 \%$ of schools (24/32) had a garden (score of 1 or higher), six of which had only launched gardening initiatives in the year prior to assessment. Gardens varied in size and scope and were used for diverse purposes including teaching activities related to healthy eating, cooking, plant science and agriculture. Most gardens primarily grew vegetables and/or fruit, while one grew only herbs. Products from the gardens were used in diverse and creative ways. For example, produce was used for school salad bars or hot lunch programmes (albeit usually contributing only a small amount to the total quantity of food served), in classroom cooking activities to teach concepts from basic maths to culinary arts skills and for school fundraisers. Although the scores on the garden domain were not statistically significantly different, elementary schools used their gardens more frequently than secondary schools and often involved more students and classrooms throughout the school (Table 2). Additionally, two elementary schools had the most highly developed gardens where garden-related activities were available to all grades (earning a score of 4). No secondary school garden programmes were as fully developed or integrated as the two most innovative elementary schools and no secondary schools received a score greater than 3 (Fig. 2). However, two secondary schools had recently partnered with a community-based organization to establish 'schoolyard market gardens', which aimed to become commercially viable, educational farms housed on school grounds $^{(47)}$. 


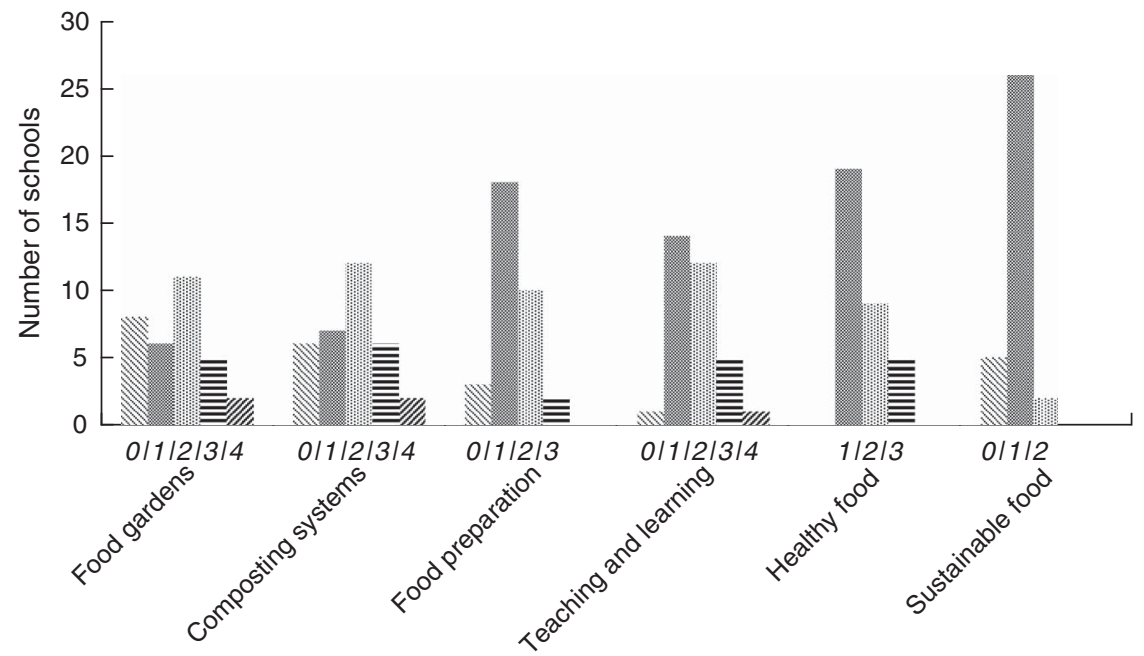

Fig. 1 Distribution of scores ( developed and integrated (4)) on the six food system environment domains of the School Food Environment Assessment Tools $(\mathrm{SFEAT})$ for all schools $(n 33)^{\star}$, Vancouver, Canada. ${ }^{*} n 32$ for food gardens score

Table 2 Descriptive statistics of scores on the six food system environment domains of the School Food Environment Assessment Tools (SFEAT) among elementary and secondary schools, Vancouver, Canada

\begin{tabular}{|c|c|c|c|c|c|c|c|}
\hline & \multicolumn{2}{|c|}{ All schools ( $n$ 33) } & \multicolumn{2}{|c|}{ Elementary schools $(n 18)$} & \multicolumn{2}{|c|}{ Secondary schools ( $n$ 15) } & \multirow[b]{2}{*}{$P$ value } \\
\hline & Median & Range & Median & Range & Median & Range & \\
\hline Food gardens† & 2 & $0-4$ & 2 & $0-4$ & 1 & $0-3$ & 0.419 \\
\hline Composting systems & 2 & $0-4$ & 2 & $0-4$ & 2 & $0-3$ & 0.539 \\
\hline Food preparation activities & 1 & $0-3$ & 1 & $0-3$ & 2 & $1-2$ & 0.017 \\
\hline Food-related teaching and learning activities & 2 & $0-4$ & 2 & $0-4$ & 1 & $1-3$ & 0.289 \\
\hline Availability of healthy food & 1 & $1-3$ & 1.5 & $1-3$ & 1 & $1-3$ & 0.704 \\
\hline Availability of environmentally sustainable food & 1 & $0-2$ & 1 & $0-1$ & 1 & $0-2$ & 0.371 \\
\hline
\end{tabular}

The domain scores can be interpreted as follows: $0=$ nothing happening in this area; $1=$ initial steps have been taken; $2=$ initiatives are happening regularly and engage some members of the school community; 3 =initiatives are happening often and engage many members of the school community (in multiple ways, if relevant); 4 =exceptional progress has been made with full integration within the school.

*Differences in the distribution of scores were compared between elementary and secondary schools using the Fisher's exact test (using $P<0.05$ to determine statistical significance).

†Sample size for food gardens score was thirty-two due to insufficient data available to reach consensus about garden use and development in one elementary school.

\section{Composting systems}

The majority of schools (27/33) had a compost system of some form (Fig. 1). Three-quarters of these schools (20/ 27) earned a score of 2 or higher, indicating that their system was operational and engaged at least some members of the school. Schools were approximately normally distributed across the five-point compost score, yet varied greatly in approaches to administration and implementation, including the variety of materials composted and the type and scale of the system. For example, some schools had collection bins in limited locations such as a staff room, while others had highly developed systems to dispose of waste from kitchens/cafeterias, cooking classes, student and staff meals, as well as yard or garden clippings. Composters ranged from small in-class or outdoor worm bins, to single-bin and higher-volume systems, and were managed by various stakeholders including students, staff or community partners. Finished compost was used primarily in school gardens; however, one school donated compost to a community pickup system and another's was used by an urban agriculture initiative that grows food on their (and other) school grounds. Overall, elementary and secondary schools were quite similar for the compost domain (Table 2).

\section{Food preparation activities}

Figure 1 shows that $91 \%$ of schools had at least some food preparation facilities or activities at their school (30/33 had a score of 1 or higher). Slightly more than half of the sample $(18 / 33)$ had taken only initial steps to offer food preparation activities (score of 1), with nearly one-third (10/33) having food preparation as a regular activity for some students (score of 2). Compared with elementary schools, secondary schools offered more regular food preparation activities ( $P=0.017$; Table 2). In elementary schools, the frequency with which food preparation facilities were used ranged 
(a)

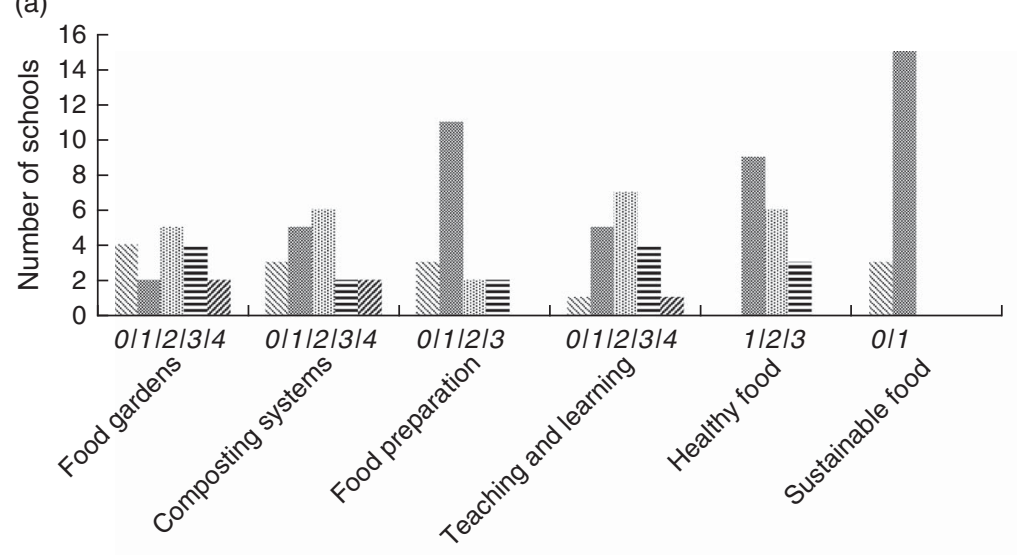

(b)

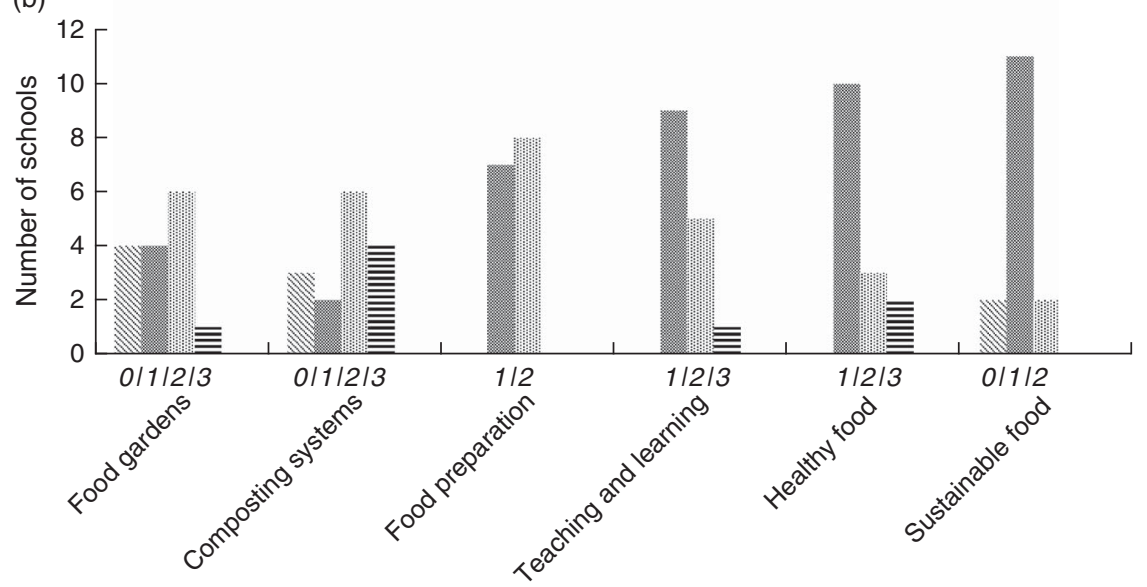

Fig. 2 Distribution of scores (ㅆ, nothing happening (0); : developed and integrated (4)) on the six food system environment domains of the School Food Environment Assessment Tools (SFEAT) for (a) elementary schools $(n 18)^{*}$ and (b) secondary schools ( $n$ 15), Vancouver, Canada. * $n 17$ for food gardens score

from a few times per year to weekly. Food preparation was used to teach a range of subjects, for after-school programmes and occasionally by community organizations offering food preparation activities. However, this was not the case in secondary schools where food preparation was most often included in home economics courses, and occasionally as part of other relevant classes such as career and personal planning and science courses, or in extracurricular clubs (e.g. sustainability and business clubs). Some secondary schools ran a basic or advanced culinary arts programme, where students prepare meals to be sold in the school cafeteria.

\section{Food-related teaching and learning activities}

All but one school integrated some food-related teaching and learning within classroom activities (Fig. 1). Most schools had only recently begun to incorporate activities into the classroom (14/33) or were doing so on a regular basis for only some students (12/33; a score of 1 and 2, respectively). Although not statistically significant, there were more elementary schools with well-developed foodrelated classroom activities, both informal and formal, than secondary schools (Table 2). Among elementary schools, examples of classroom activities included taste tests and cooking competitions, as well as using food to build cultural awareness among diverse student groups. One elementary school reported integrating the entire food cycle into teaching and learning activities, including English, art, maths and social science subjects. All secondary schools had some formal integration of food-related activities within the curriculum, but only one school reported such activities as being available in every grade. In secondary schools, the food-related teaching and learning activities were most commonly reported as part of home economics courses, where students may learn about food safety or food preparation, for example. Nutrition education was also frequently described as being incorporated into physical education and health and career courses.

\section{Availability of bealthy food}

No school scored a 0 on the healthy food availability domain, indicating that all schools had made at least some effort to make healthy options available (Fig. 1). Many schools (24/33) indicated participating in the BC School 
Fruit and Vegetable Nutritional Program, which provides fresh BC produce bimonthly as snacks in kindergarten to grade 12 classrooms across the province ${ }^{(48)}$. Schools also reported offering other healthy food options in the cafeteria or as part of a school meal programme and frequently mentioned providing items including low-fat milk and whole grains.

Direct assessment of cafeterias, school stores, vending machines, other special food days and fundraisers revealed that nearly all schools (28/33) continued to sell items prohibited under the Guidelines such as sugarsweetened beverages and snack foods high in sodium and fat content (e.g. potato chips). Moreover, the frequency of school food fundraisers varied from none or only a few per year to weekly; and fundraisers often still sold noncompliant items, including French fries or potato chips containing $0.2 \mathrm{~g}$ trans fats or more and $15 \mathrm{~g}$ of fat or more per serving ${ }^{(24)}$. Overall, no school fully followed the Guidelines pertaining to nutritional quality of available foods. Patterns were similar between elementary and secondary schools, where despite the fact that schools consistently made healthy foods available to students, many still sold unhealthy items. As a result, no school scored higher than 3 out of 4 on this domain (Fig. 2).

\section{Availability of environmentally sustainable food}

The distribution of the environmentally sustainable food domain indicates that most schools (28/33) made an effort to provide food choices proposed to be supportive of environmental sustainability goals ${ }^{(7,25,26)}$. Sustainable initiatives included using foods produced locally, organically or in the school garden, selling minimally processed whole foods with less/minimal packaging and making vegetarian options available. Slightly more than threequarters (26/33) of schools scored a 1 on this domain, characterized as taking only initial steps to provide environmentally sustainable options. Just two schools (both secondary) offered sustainable foods on a regular basis, scoring a 2 . No schools were categorized as having environmentally sustainable food options always available or fully integrated within their school; scores were similar between elementary and secondary schools for this domain (Table 2).

\section{Discussion}

The present study describes a method for gaining insight into and catalysing dialogue about domains where progress within school food environments has been or could be made. In Vancouver, SFEAT revealed that many schools have begun efforts pertaining to both healthy and environmentally sustainable food-related initiatives, although uptake varied widely between schools and across domains. Schools scored highest overall in the areas of food garden and compost system availability and use, where the proportion of schools with initiatives occurring on a regular basis and involving many students and staff was largest. Several schools also regularly integrated hands-on food preparation experiences and food-related teaching and learning activities into school mandates. Yet, despite increasing calls for ensuring access to nutritious foods at school ${ }^{(9,10)}$, the healthy food availability domain lagged compared with most others. Similarly, few schools demonstrated widespread integration of food-related environmental sustainability initiatives. As a whole, findings indicate that the distribution of scores for all domains was either roughly normal or skewed right and no median score exceeded 2 . These findings suggest that there is still ample opportunity for progress within all aspects of the school food environment to move towards more initiatives happening often and engaging many members of the school community' or 'exceptional progress, with full integration within the school'.

The proliferation of school gardens in three-quarters of this Vancouver sample exceeds recent national estimates that only $15 \%$ of Canadian schools offer gardening activities $^{(49)}$. Few estimates are available with which to compare availability of Vancouver's school composting programmes with national or other municipal estimates. However, at the time of the present study, over $80 \%$ of Vancouver schools had a compost system in place and the remainder were expected to gain access as the city transitions to district-wide compost collection in $2014^{(50)}$. It is possible that current findings slightly overestimate garden and composting integration in Vancouver, since more engaged schools could have been more likely to participate in the study than typical schools. However, this sample included over three-quarters of all secondary schools and a diverse mix of elementary schools. Hence, although potentially biased upward, levels of engagement around garden and composting activities more likely reflect pervasive trends across the city catalysed by inputs from school board partners and local grass-roots food systems advocates promoting garden-based learning as a strategy for supporting improved dietary outcomes and environmental stewardship ${ }^{(51,52)}$

Regular integration of food-related teaching and learning activities and hands-on food preparation experiences into school mandates was also relatively popular in this sample. Similarly, a recent study of over 400 schools across Canada suggests that cooking classes and healthy eating-related media literacy education are now fairly common in Canadian schools (reported in 59\% and $67 \%$ of sampled schools, respectively) ${ }^{(49)}$. Yet, national estimates are based only on reported availability of 'any' healthy eating education opportunities reported by school administrators and not level of engagement with those programmes. It is therefore not possible to compare the extent to which food-related educational opportunities are integrated throughout schools nationally, or how incorporation of educational experiences in Vancouver 
compares with schools across Canada. In Vancouver, progress with food preparation activities was more advanced in secondary schools, most likely because of home economics courses, which have food preparation skills modules built into curricula. At the elementary school level, most food preparation activities were classroom-specific and frequently only occurred on a small scale led by a very engaged teacher or as a one-time lesson or unit given by an outside community organization.

More broadly defined food-related teaching and learning activities (that do not necessarily require food preparation infrastructure) existed to some degree at most schools, yet also were not well integrated across the entire school curriculum. All secondary schools had integrated food-related topics, usually within home economics, physical education or health and career education courses; however, elementary schools typically offered more developed teaching and learning activities related to the food cycle within classrooms. This may reflect the greater flexibility available to elementary teachers to incorporate innovative ways of teaching about the food cycle into different subjects. Our research team is also developing more in-depth assessment approaches to better gauge whether students are exposed to the entire food cycle (i.e. from food production through consumption and waste disposal) or rather learning about discrete elements of the food system in isolation ${ }^{53)}$. Given evidence that urban schoolchildren hold a 'black box' with limited understanding about how food is transformed between the farm and food store ${ }^{(54)}$, further research is needed to examine impacts of food-related learning activities and their integration on student-level outcomes.

Both the healthy food and environmentally sustainable food availability domains scored lowest compared with other domains. While most schools offered some healthy options to students and most stakeholders noted an attempt to conform to the Guidelines for Food and Beverage Sales in BC Schools, analyses of actual food availability indicated that nearly all schools sold prohibited items. Although the Guidelines were originally mandated for all public schools in 2008, our findings were similar to a 2005 study of BC schools where 'less healthy' items (e.g. sugar-sweetened beverages, candy bars) were widely available across schools ${ }^{(34)}$. Current findings and those from other Canadian school assessments indicate that progress towards improving the quality of food available within schools is still needed ${ }^{(49)}$.

Likewise, availability of environmentally sustainable food options is still relatively low. There are currently few formally established incentives for schools to move towards sustainable options and ambiguity remains surrounding the definitions, best practices and benefits of offering sustainable choices. It was therefore not surprising that most initiatives were relatively diffuse, small scale and ad hoc. Developing a clear definition of sustainable food and ideas for action that are communicated regularly to stakeholders coupled with institutionalized policies, incentives and professional development for food-service workers and those making procurement and sales decisions could further nurture current efforts.

\section{Implications and limitations}

While the body of research surrounding school food systems is increasing, this emerging field lacks generalizable assessment tools and a common language for describing the multiple domains where schools are taking action. The current study therefore presents a method for evaluating school food environments and engagement with key aspects of the school food system which schools or researchers could adapt and apply in diverse school settings to examine needs and opportunities for action and progress over time. Documenting these factors is particularly important in cities like Vancouver where the school food context is changing rapidly.

The SFEAT was developed to assess six key domains but takes into account the individuality of schools and allows users to adapt and apply the tools in a variety of ways. For example, the SFEAT could be used in its current form as a needs assessment tool to gain initial understanding of the level of engagement for each domain or to determine opportunities for future action. Alternatively, the tool could be modified to suit other local, regional or national contexts through a similar iterative and collaborative process in an effort to narrow topic areas that are of priority or to generate new domains for programme planning.

Several strengths and limitations of the current findings and SFEAT approach are important to note. First, this sample included only public schools from one urban area and may not reflect trends outside Vancouver's public schools. Second, data collection efforts were time-intensive and incorporated three tiers of data collection (school appraisals and interviews with two informants) coupled with a team-based scoring system. While the SFEAT interviewees spoke to certain aspects of the school food environment, most could not comment on the full variety of food-related initiatives across their school. Given the complexity of multiple ongoing initiatives, no single teacher, administrator or foodservice worker was fully aware of the numerous initiatives taking place in all contexts, which necessitated gathering input from more than one key respondent. This level of input may not be feasible for assessments of schools located across large geographical areas or with higher sample sizes (e.g. provincial or national samples or multi-city evaluation projects). Still, the framework and indicators described in Table 1 could be examined using less resource-intensive methods. For example, we are currently developing a brief self-assessment tool that asks schools to more simply rank their progress (and future areas for action) across the six domains, and next steps will be to validate this brief assessment compared with the rigorous data collection process reported in the current study. 
Future users should also keep in mind the qualitative nature of the scoring system. The SFEAT draws on a 'systems approach ${ }^{, 55-57)}$ by incorporating numerous indicator questions into the scoring process to understand a complex system. Using multiple items within each domain and perspectives from three data collection approaches created a more complete picture of the availability and use of foodrelated actions within schools, and incorporating team discussion and first-hand knowledge of school settings into scoring decisions was a particular strength of the data analysis process. However, given the contextual differences between schools, the subjective nature of some responses and the multifaceted aspects of school food environments, it is important to recognize that these domains do not always neatly fit into distinct, fixed quantitative categories. Therefore, this approach is ill suited for the examination of specific quantitative indicators or for tracking very small or specific differences in food availability or school food production. For example, SFEAT was not designed to track specific nutritional content (e.g. grams of trans fats or sodium in vending machines, specific land area used for gardening, weight or energy provided by garden harvest or volume of food waste collected). These specific questions and metrics can certainly be integrated into data collection approaches and can inform the qualitative domain scoring process.

Given the cross-sectional nature of the study design, we cannot make causal claims about why some schools are more engaged in food systems initiatives than others and did not specifically probe the underlying determinants of progress within each school. But overall, this approach provides a broad but valuable sense of where schools 'are at'. Moreover, in the context of the present study, the SFEAT process often catalysed dialogue about healthy and sustainable food systems among interview participants, potentially deepening their awareness of health and sustainability issues and areas for future action.

\section{Conclusions}

Overall, some level of engagement was documented across all six domains of the school food environment among Vancouver schools, particularly with respect to development of gardens and composting systems. However, more comprehensive strategies, including funding, training, support and advocacy, will likely be necessary to increase the availability of healthy and environmentally sustainable food within these schools and to more fully integrate programmes and policies both school- and district-wide. Future research applying the SFEAT approach could contribute to improved understanding of the ways that school food environments influence short- and long-term dietary outcomes, environmental stewardship knowledge and food practices among children and adolescents. Given the complexity and recent growth of this field of research and the scope of interventions and advocacy, tracking school progress with respect to these domains is valuable and worth pursuing. The scoring system described in the present study offers a pragmatic approach to understand the relative state of a school's engagement in initiatives that support healthy eating and environmentally sustainable food systems and to move research in this area forward.

\section{Acknowledgements}

Financial support: Funding support was from a Community University Research Alliances grant from the Social Sciences and Humanities Research Council of Canada (from the Think\&EatGreen@School project). Additional support was received from a Canadian Institute of Health Research (CIHR) Operating Grant related to the Food Practices on School Days Study; and C.E.V. received funding from a CIHR fellowship. The funders had no role in the design, analysis or writing of this article. Conflicts of interest: None. Authorship: J.L.B. and G.E.C. designed the study in collaboration with S.C., A.R. and the Think\&EatGreen@School coordinating committee, and contributed to oversight of data collection, analysis and manuscript preparation. J.E. and S.S. contributed meaningfully to data collection, including school recruitment, the design and revision of data collection tools, and training and management of data collection personnel. N.A. and C.E.V. participated in data analysis, preparation of key tables and figures, and critical revisions to the manuscript text. C.E.V. provided additional coordination, data collection support and led a substantial portion of the manuscript writing process in collaboration with J.L.B. T.S. supported recruitment efforts and all authors were involved in the revision and final approval of the manuscript. Ethics of buman subject participation: The study met the guidelines laid down in the Declaration of Helsinki and all procedures involving human subjects were approved by the Behavioural Research Ethics Board at the University of British Columbia and the Vancouver Board of Education. Written consent was obtained from participating school stakeholders.

\section{References}

1. Nicklas TA, Hayes D \& American Dietetic Association (2008) Position of the American Dietetic Association: nutrition guidance for healthy children ages 2 to 11 years. J Am Diet Assoc 108, 1038-1044, 1046-1047.

2. Fanjiang G \& Kleinman RE (2007) Nutrition and performance in children. Curr Opin Clin Nutr Metab Care 10, 342-347.

3. Bryan J, Osendarp S, Hughes D et al. (2004) Nutrients for cognitive development in school-aged children. Nutr Rev 62, 295-306.

4. Gussow J \& Clancy K (1986) Dietary guidelines for sustainability. J Nutr Educ 18, 1-5. 
5. Hamelin AM, Lamontagne C, Ouellet D et al. (2010) Healthful eating: beyond food, a global concept. Can J Diet Pract Res 71, e21-e27.

6. Lang T \& Heasman M (2004) Food Wars: The Global Battle for Mouths, Minds and Markets, 2nd ed. London: Routledge.

7. Harmon A \& Gerald B (2007) Position of the American Dietetic Association: food and nutrition professionals can implement practices to conserve natural resources and support ecological sustainability. J Am Diet Assoc 107, 1033-1043.

8. Rojas A, Valley W, Mansfield B et al. (2011) Toward food system sustainability through school food system change: Think\&EatGreen@School and the making of a community-university research alliance. Sustainability $\mathbf{3}$, $763-788$.

9. Institute of Medicine (2012) Accelerating Progress in Obesity Prevention: Solving the Weight of the Nation. Washington, DC: The National Academies Press.

10. Public Health Agency of Canada (2012) Curbing Childhood Obesity: A Federal, Provincial and Territorial Framework for Action to Promote Healthy Weights. http://www.phac-aspc. gc.ca/hp-ps/hl-mvs/framework-cadre/index-eng.php (accessed October 2013).

11. Jones M, Dailami N, Weitkamp E et al. (2012) Food sustainability education as a route to healthier eating: evaluation of a multi-component school programme in English primary schools. Health Educ Res 27, 448-458.

12. Farm to Cafeteria Canada (2012) What is Farm to Cafeteria Canada? http://www.farmtocafeteriacanada.ca/wp-content/ uploads/2014/10/F2CC_ContactUS_EN.pdf (accessed February 2014).

13. US Department of Agriculture (2015) Farm to School. http:// www.fns.usda.gov/farmtoschool/farm-school (accessed February 2015).

14. Taylor J \& Johnson R (2013) Farm to school as a strategy to increase children's fruit and vegetable consumption in the United States: research and recommendations. Nutr Bull 38, 70-79.

15. Social Research and Demonstration Corporation (2010) Evaluation of the Farm to School Salad Bar initiative: Executive Summary. http://www.srdc.org/uploads/BCHLA_ SaladBar.pdf (accessed February 2014).

16. Joshi A, Azuma A \& Feenstra G (2008) Do farm-toschool programs make a difference? Findings and future research needs. J Hunger Environ Nutr 3, 229-246.

17. Think\&EatGreen@School (2014) 2013-2014 Annual Report. http://thinkeatgreen.ca/files/2014/12/FINAL-ThinkandEat Green-Annual-Report-FINAL_Dec2_WebVersion.pdf (accessed January 2014).

18. City of Vancouver (2013) Vancouver's Food Strategy: Building just and sustainable systems. http://vancouver.ca/ people-programs/vancouvers-food-strategy.aspx (accessed February 2014).

19. Millsip K (2010) Sustainability Framework for the Vancouver School Board. http://www.vsb.bc.ca/sites/default/files/ publications/SUSTAINABILITY\%20FRAMEWORK\%202.pdf (accessed February 2014).

20. Atkinson RA, McKenna ML, Bays J et al. (2013) Local Foods: Canadian schools, campuses, and health care facilities speak up. http://www.farmtocafeteriacanada.ca/wp-content/uploads/ 2013/10/Report-Local-Foods-Canadian-schools-campuses-andhealth-care-facilities-speak-up-2013.pdf (accessed February 2014).

21. Stewart-Brown S (2006) What is the Evidence on School Health Promotion in Improving Health or Preventing Disease and Specifically What is the Effectiveness of the Health Promoting Schools Approach? Health Evidence Network Report. Copenhagen: WHO Regional Office for Europe; available at http://www.euro.who.int/document/e88185.pdf
22. Healthy Schools BC (2013) CSH Knowledge Guide. http:// healthyschoolsbc.ca/media/8768/csh_knowledge_guide_electronic_copy_final_2013.pdf (accessed February 2015).

23. Health Canada (2011) Eating Well with Canada's Food Guide. http://www.hc-sc.gc.ca/fn-an/food-guide-aliment/ index-eng.php (accessed February 2013).

24. BC Ministry of Education \& Ministry of Health (2010) Guidelines for Food and Beverage Sales in BC Schools Ministry of Education \& Ministry of Healthly Living and Sport. http://www.bced.gov.bc.ca/health/2010_food_guidelines.pdf (accessed September 2012).

25. American Medical Association (2009) Report 8 of the Council on Science and Public Health (A-09): Sustainable food. http:// www.ama-assn.org/resources/doc/csaph/csaph-rep8-a09.pdf (accessed February 2014).

26. Department of Health and Human Services, General Services Administration (2012) The Health and Sustainability Guidelines for Federal Concessions and Vending Operations. http:// www.cdc.gov/chronicdisease/pdf/guidelines_for_federal_ concessions_and_vending_operations.pdf (accessed February 2014).

27. BC Dairy Foundation, Ministry of Health \& Knowledge Network (2010) Act Now BC. Making it Happen: Healthy Eating at School.School Healthy Eating Assessment Tool. http://healthyeatingatschool.ca/uploads/school-healthy-eatingassessment-tool.pdf (accessed February 2015).

28. BC Ministry of Education \& Ministry of Health (2007) Guidelines for Food and Beverage Sales in BC Schools. http://www.bced.gov.bc.ca/health/guidelines_sales07.pdf (accessed October 2013).

29. Valleau L Froats-Emond C, Neumann S et al. (2007) Nutrition Tools for Schools: A Toolkit for Ontario Health Units to Support Elementary Schools in Creating a Healthy Nutrition Environment. http://www.hamilton.ca/Healthand SocialServices/PublicHealth/Nutrition/NutritionToolsForSchools. htm (accessed February 2015).

30. Strange K (2010) Guidelines for Food and Beverage Sales in BC Schools Implementation Review Report. Vancouver, BC: Ministry of Education.

31. Kroeker C, Manske S \& Beyers J (2008) Provincial Implementation of the 2007-2008 School Health Environment Survey. Waterloo, ON: University of Waterloo.

32. BC Ministry of Education \& Ministry of Healthy Living and Sport (2008) School Meal and School Nutrition Program Handbook. http://www.bced.gov.bc.ca/communitylink/pdf/ smph.pdf (accessed February 2014).

33. Government of Manitoba (2007) Manitoba School Nutrition Survey. Manitoba Health \& Healthy Living. http:// www.gov.mb.ca/healthyschools/foodinschools/index.html (accessed February 2014).

34. Rideout K, Levy-Milne R, Martin C et al. (2007) Food sales outlets, food availability, and the extent of nutrition policy implementation in schools in British Columbia. Can J Public Health 98, 246-250.

35. Welsh Assembly Government (2004) Food in school assessment tool: a tool for monitoring and evaluating a whole school approach to food and nutrition, http://dera. ioe.ac.uk/8638/ (accessed February 2014).

36. Carter MA \& Swinburn B (2004) Measuring the 'obesogenic' food environment in New Zealand primary schools. Health Promot Int 19, 15-20.

37. Finch M, Begley A, Sutherland R et al. (2007) Development and reproducibility of a tool to assess school foodpurchasing practices and lifestyle habits of Australian primary school-aged children. Nutr Diet 64, 86-92.

38. Rimkus L, Jones P \& Ona F (2004) Results from the 2003 Feasibility Study: The San Francisco Farm-toSchool Report. San Francisco, CA: San Francisco Food Systems. 
39. Centers for Disease Control and Prevention (2005) School Health Index. A Self-Assessment and Planning Guide. Elementary School Version. Atlanta, GA: CDC.

40. Centers for Disease Control and Prevention (2006) Healthy Youth. School Health Policies and Practices Study: School Policy and Environment School Questionnaire http://www. cdc.gov/HealthyYouth/shpps/index.htm (accessed February 2014).

41. National Coalition for Food-Safe Schools (2004) Food-Safe Schools Action Guide: Food-Safe Schools, Needs Assessment and Action Plan. http://www.foodsafeschools.org/ (accessed October 2010).

42. Birnbaum A (2002) Are differences in exposure to a multicomponent school-based intervention associated with varying dietary outcomes among adolescents? Health Educ Behav 29, 427-443.

43. US Department of Agriculture (2000) Changing the Scene. http://www.fns.usda.gov/tn/resources/changing.html (accessed October 2010).

44. Dotmocracy.org (2014) What is Dotmocracy 2015. http:// www.dotmocracy.org/what_is (accessed January 2015).

45. Greenwood P \& Nikulin MS (1996) A Guide to Chi-Square Testing. New York: Wiley \& Sons, Inc.

46. BC Ministry of Education (2011) School Information. http:// www.bced.gov.bc.ca/apps/imcl/imclWeb/SchoolContacts.do (accessed January 2011).

47. Fresh Roots Urban Farm (2012) About Us. http://freshroots. ca/ (accessed August 2014).

48. BC Ministry of Health (2010-2013) BC School Fruit and Vegetable Nutritional Program. http://sfvnp.ca (accessed December 2013).
49. Browning HF, Laxer RE \& Janssen I (2013) Food and eating environments in Canadian schools. Can J Diet Pract Res $\mathbf{7 4}$, 160-166.

50. Vancouver Board of Education (2011) Resource Use and Waste reduction action plan. http://www.vsb.bc.ca/sites/ default/files/publications/VSB\%20WASTE\%20Action\%20Plan. Draft\%203.3.pdf (accessed February 2014).

51. Robinson-O'Brien R, Story M \& Heim S (2009) Impact of garden-based youth nutrition intervention programs: a review. J Am Diet Assoc 109, 273-280.

52. Vancouver Board of Education (2010) Garden Policy. http:// www.vsb.bc.ca/district-policy/io-garden-policy (accessed November 2013).

53. Stephens $\mathrm{T}$ (2014) Participation in School Food and Nutrition Programs and Associations with Dietary Psychosocial and Behavioural Outcomes Among Vancouver Students in Grades 6-8. Vancouver, BC: University of British Columbia.

54. Calabrese Barton A, Koch PD, Contento IR et al. (2005) From global sustainability to inclusive education: understanding urban children's ideas about the food system. Int J Sci Educ 27, 1163-1186.

55. Bawden RJ, Macadam RD, Packham RJ et al. (1984) Systems thinking and practices in the education of agriculturalists. Agric Syst 13, 205-225.

56. Capra F (1997) The Web of Life: A New Scientific Understanding of Living Systems. New York: Anchor Books.

57. Checkland P (1999) Systems Thinking, Systems Practice: Includes a 30-Year Retrospective. Chichester: Wiley. 